\title{
DIAGNÓSTICO DE SALUD BUCAL DEL PRIMER CONTIN- GENTE DE LA FUERZA DE TAREA CONJUNTA TOROGOZ DE EL SALVADOR. MISIÓN INTERNACIONAL DE PAZ EN MALI
}

\author{
Jossette Arleen Rodríguez de Cáceres ${ }^{1}$ \\ Manuel Remberto Pineda Hernández ${ }^{2}$ \\ Yesenia Guadalupe Arévalo de Roque ${ }^{3}$ \\ Ruth Elizabeth Fuentes de Sermeño ${ }^{4}$ \\ Recibido 02/06/16 \\ Aceptado 24/11/216
}

\section{RESUMEN}

La Intervención militar en Malí fue una operación llevada a cabo desde 2013 por Francia y el gobierno de Malí en la Operación Serval, con el apoyo de varios países africanos y occidentales. El Objetivo general de este estudio fue el de diagnosticar el estado de salud bucal de la población militar perteneciente al primer contingente, entre enero y febrero del 2015. Según la OMS las condiciones de empleo y trabajo constituyen un determinante social de la salud y calidad de vida; para el caso del desempeño militar suponen mayores factores de riesgos de seguridad dada la naturaleza de su misión que pueden influir directamente en el estado psicológico y de salud del personal. Investigación de tipo Cuantitativa, transversal y prospectiva, las unidades de análisis fueron 90 sujetos pertenecientes a la Compañía de la Misión Naciones Unidas para Mali (MINUSMA). El criterio de inclusión fueron todos los miembros del mismo. La prevalencia de caries dental en la población estudiada, establecido por medio del índice CPOD es de 17.34, un índice muy alto según lo establece la literatura, con un aceptable estado de salud general. En cuanto a los hábitos y prácticas de salud bucal un aproximado del $80 \%$ dijo tener buenos hábitos de salud bucal contrastando con los altos índices de caries que poseen. Estos datos revelan que es de suma importancia, sobre todo para instituciones prestadoras de servicio de salud, la creación de proyectos encaminados a la promoción de la salud; enfatizando un refuerzo educativo integral, mejorando prácticas y conocimientos que impacten a lo largo del ciclo de la vida.

Palabras clave: El Salvador, hábitos, prácticas, salud bucal.

\section{ORAL HEALTH DIAGNOSIS OF THE FIRST JOINT TASK FORCE TOROGOZ. PEACE OPERATION IN MALI}

\section{SUMMARY}

Between january and february 2015, an oral health diagnosis was made to the first salvadorean contingent that participated in the Integrated Multidimensional Mission of Stabilization of the United Nations in Mali, called Torogoz. A peace operation approved by the Security Council of the UN in april 2013, because of the coup in this african republic that receives police and military support from 122 countries until now. Following the health protocol that governs the Military Health Command and the Peace Operation Training Center of the Armed Force of El Salvador, the

\footnotetext{
1 Dra. Jossette Arleen Rodríguez de Cáceres. Coordinadora del Observatorio de Salud Bucodental de la UEES, jossette. caceres@ uees.edu.sv, número de filiación N-CONACYT 0814-081215

2 Cap. Dr. Manuel Remberto Pineda. Comandante de la Sección de Sanidad, dentalgroup503@gmail.com

3 Dra. Yesenia Guadalupe Arévalo de Roque. Docente Titular Cátedra Salud Pública y Odontología Preventiva UEES, yesenia. arevalo@uees.edu.sv, número de filiación N-CONACYT 0786-130715

4 Dra. Ruth Fuentes de Sermeño. Decano de la FOUEES. ruth.sermeno@uees.edu.sv
} 
90 members of Torogoz were examinated to meet the physical and psychological requirements that mission demanded. Specially because this contingent includes only a minority of officers and non comissioned officers with permanent medical attention. In the mean time, the majority of soldiers come from a troop with irregular participation in the army and limited benefits. The result of this quantitative, transversal and prospective investigation about oral health of this provisional Task Force revealed a high prevalence of dental caries despite the majority study subjects recognized the associated risk factors and the benefit of the regular practice of oral health.The research coincides with the World Health Organization about the direct relation between working conditions and quality of life. In that sense, the article offers a reflection about professions and trades of high risk such as militia where stress and health promotion significantly affect the performance and public health costs.

Keywords: Oral health, Peace Operation, El Salvador

\section{INTRODUCCIÓN}

Las condiciones de empleo y trabajo constituyen un determinante social de la salud y calidad de vida $^{1,2}$ que, para el caso de las condiciones del trabajo militar suponen mayores factores de riesgos a la seguridad dada la naturaleza de su misión, que pueden influir directamente en el estado psicológico del personal.

El modelo conceptual de causalidad en salud laboral asume que la salud y los daños a la salud están relacionados con las condiciones en que las personas realizan su trabajo, fruto de la interacción de múltiples determinantes abordados desde diferentes niveles de análisis sistémico, social, individual y biológico ${ }^{3}$.

Tras los acuerdos de paz, se inicia una nueva era para el estamento de sanidad militar. Su traslado al nuevo edificio en el año de $1991 \mathrm{y}$, la desmovilización del ejército, implica retos dentro de los cuales el Batallón de Sanidad Militar, fue el único batallón que no fue desmovilizado por los Acuerdos de $\mathrm{Paz}^{4}$ y que gracias a acuerdos internacionales de cooperación con los países con los cuales El Salvador mantiene relaciones, como los Estados Unidos, es que éstos han participado en Misiones Oficiales de Pacificación entre los que se menciona Irak y otros.

En ese contexto es que nace el contingente "Misión internacional de las Naciones Unidas en Mali" (MINUSMA), nombre de la Misión de la ONU en Mali. Para la Fuerza Armada de
El Salvador es algo histórico, por ser la primera vez que el país participa con un contingente de manera auto sostenible sin participar bajo bandera de otro país ${ }^{5}$. Para el mantenimiento de paz en la República de Mali.

En noviembre de 2013, se concentró al personal que conformaría el Contingente MINUSMA en las instalaciones de CEOPAZ (Centro de Entrenamiento para Operaciones de Paz), con especialistas de diferentes unidades de la Fuerza Armada de El Salvador y da inicio el proceso de enviar la misión con destino a la República de Mali en el continente africano ${ }^{6}$.

La Intervención militar en Malí fue una operación llevada a cabo desde enero de 2013 por Francia y el gobierno de Malíen la Operación Serval en el norte de ese país con el apoyo de varios países africanos y occidentales, bajo el amparo de la ONU, con el objetivo de prestar apoyo al proceso político y llevar a cabo tareas de estabilización relacionadas con la seguridad, prestando especial atención a los principales centros de población y las líneas de comunicación, la protección de los civiles, la vigilancia del respeto de los derechos humanos, la creación de las condiciones necesarias para la prestación de asistencia humanitaria y el regreso de los desplazados, la ampliación de la autoridad del Estado y la preparación de elecciones libres, inclusivas y pacíficas ${ }^{6}$.

En los últimos años, Malí se ha enfrentado a una profunda crisis con graves consecuencias en los planos político, de seguridad, socioeconómico, 
humanitario y de derechos humanos. Esa crisis se debe a condiciones estructurales de larga data, como la debilidad de las instituciones del Estado; una gobernanza ineficaz; una cohesión social frágil; el sentimiento arraigado entre las comunidades del norte de que el Gobierno central no les presta atención, una sociedad civil débil y dependiente del exterior y los efectos de la degradación ambiental, el cambio climático y las crisis económicas. Esta situación se vio agravada por factores de inestabilidad más recientes, como la corrupción, el nepotismo, el abuso de poder, luchas internas y el deterioro de la capacidad del ejército nacional ${ }^{6}$.

El Ministro de la Defensa Nacional de El Salvador, General David Munguía Payés, se presentó ante la Comisión de Defensa, de la Asamblea para exponer los contenidos y argumentos para el establecimiento de una fuerza de tarea de estabilización en la República de Mali, África. La visita del Ministro tuvo como propósito convencer a los legisladores para que decreten una Ley Especial Transitoria para la aplicación de la resolución 2100 (2013), emitida por el Consejo de Seguridad de las Naciones Unidas, relativa al establecimiento de una misión multidimensional integrada de estabilización de las Naciones Unidas en Mali (MINUSMA), con la finalidad de prestar apoyo al proceso político de ese país a través de la realización de tareas de estabilización relacionadas a la seguridad ${ }^{7}$.

La Misión, según dijo el titular de la Defensa Nacional, tendría vigencia por un año, prorrogable con un costo de dos millones doscientos veinte y unos mil trescientos veinte y nueve dólares, de los cuales más de un millón 700 mil serán aportados por el gobierno de los Estados Unidos y el Ministerio de Defensa utilizará de su presupuesto un promedio de cien mil, más 376 mil de permutas 7 .

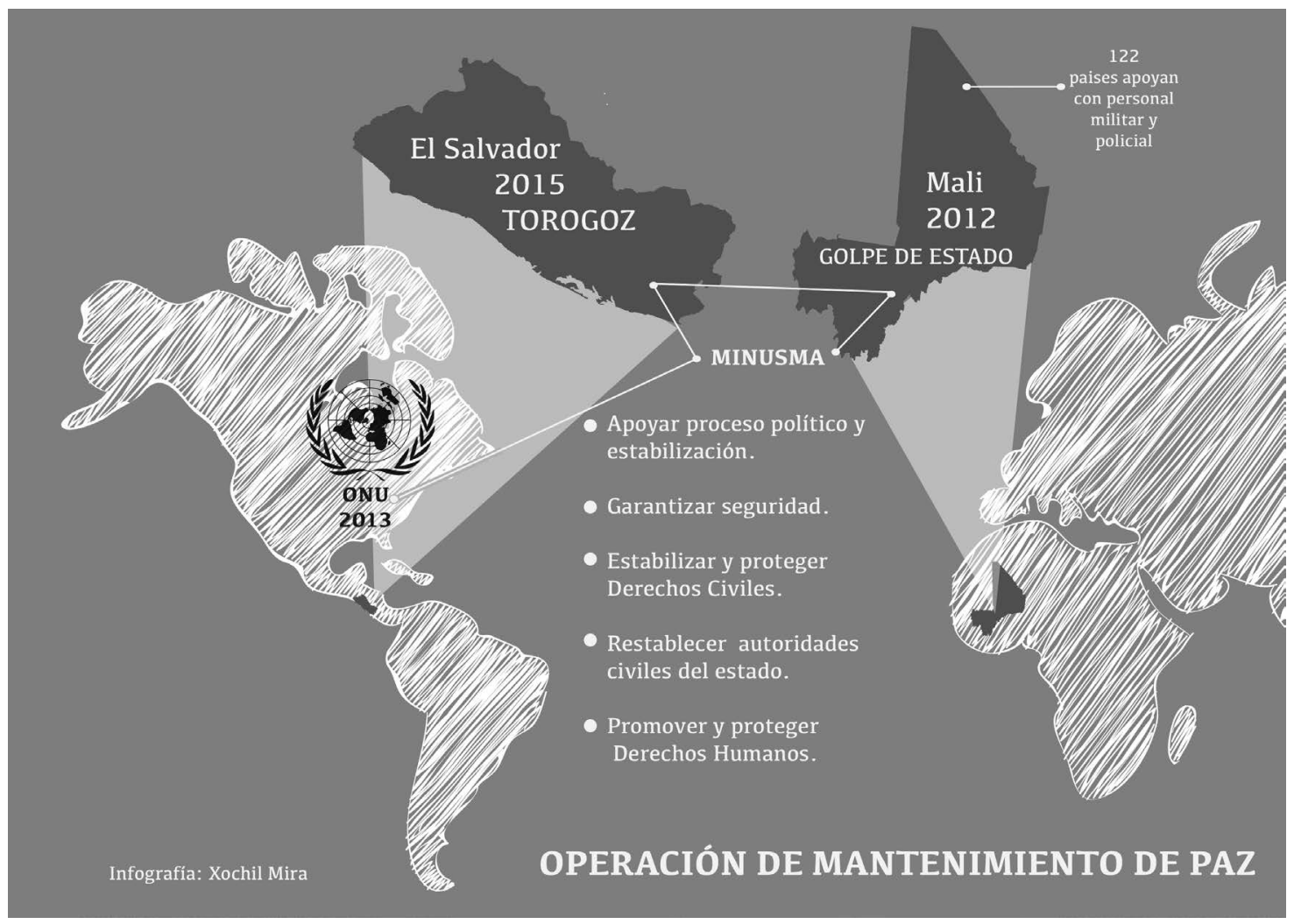


En cuanto a la salud bucal la OMS en su informe sobre el problema mundial de las enfermedades bucodentales afirma que: el dolor, los abscesos dentales, los problemas al comer o en la masticación, la pérdida de piezas y la existencia de dientes descoloridos o dañados tienen efectos importantes en la vida y el bienestar cotidianos de las personas ${ }^{8}$. Siendo que una mala salud bucodental puede tener profundas repercusiones en la salud general y en la calidad de vida.

En el esfuerzo por la profesionalización de Sanidad Militar y buscando la mejor atención para al personal de alta, en 1984 se comienza a formar en la Escuela de Sanidad Militar (ESM) a Asistentes Dentales. Con el tiempo se vuelven Higienistas Dentales empíricos, por la exigencia del servicio y por la necesidad de trabajar en la prevención de enfermedades periodontales dentro de la Fuerza Armada. En la década del 2000 inician los trabajos de investigación, encaminados a la prevención de enfermedades bucodentales, que originan programas de promoción y educación en salud bucal que se realizan hasta el día de hoy en todas las unidades militares del país .

Por tanto, este estudio pretende generar una línea base para el fortalecimiento de los programas preventivos que se realizan a todo el personal militar destacado en la Fuerza Armada. A la fecha la Institución no cuenta con datos actualizados sobre el estado de salud bucal de su población, lo que impide reorientar y focalizar la atención en aquellas enfermedades más prevalentes a nivel bucal.

\section{METODOLOGÍA}

Investigación de tipo Cuantitativa que analizó encuestas de la población en estudio, con el sistema estadístico SPSS ${ }^{\circledR} 14.0$ Es un estudio de tipo Descriptivo, prospectivo y transversal porque se llevó acabo en un solo momento en el tiempo. Las unidades de análisis fueron los 90 miembros pertenecientes al primer contingente de la Fuerza de Tarea conjunta TOROGOZ 2015. no hubo criterios de exclusión, por lo mismo que no se utilizó ninguna fórmula para obtener la muestra. Previo a la recolección de los datos, se les explico a los participantes sobre el estudio y se procedió a la firma de consentimiento informado. Luego se procedió a recolectar la información, por medio de un Instrumento previamente validado con respuestas obtenidas en 10 minutos. El Instrumento de recolección de datos contenía información general y antecedentes médico-odontológicos. Entre los datos sociodemográficos: nombre, edad y escolaridad. Con los antecedentes médico-odontológicos, se indagó enfermedades como: diabetes, asma, alergias, enfermedades cardiovasculares. Y finalmente se levantó una ficha odontológica en la que se incluyen: índice de CPO-D que mide la historia pasada de caries dental, contando los dientes cariados, perdidos y obturados, además de datos generales sobre hábitos dentales. El protocolo del estudio se evaluó el 23 de febrero de 2015 por el Comité de Ética para la investigación de la Universidad Evangélica de El Salvador, además se obtuvieron los permisos pertinentes de la Institución militar para realizar la investigación, autorizado por el Comandante del Contingente MINUSMA.

\section{ANÁLISIS Y DISCUSIÓN DE RESULTADOS.}

Esta investigación analizó las variables sociodemográficas de los miembros del primer contingente de la Fuerza de tarea conjunta TOROGOZ 2015, identificando al 96\% de la población como masculina con 36 años como media. El $60 \%$ de todos los encuestados poseen un nivel educativo de bachillerato.

En cuanto al estado de salud general, el 33\% de los encuestados hace un año visitó al médico para realizarse chequeo general; el $84 \%$ de la población encuestada no ha padecido ninguna enfermedad reciente y más del $90 \%$ de ellos no había sido hospitalizada recientemente y tampoco tomaba medicamentos por enfermedades crónicas. Solo el $5 \%$ de la población encuestada padecía de alergias por medicamentos o alimentos. 
Contrastando con estos resultados, más del 70\% percibe que su estado de salud no era mejor que el año pasado y solo el 34\% de ellos respondía que su estado de salud era excelente (Tabla 1).

Tabla 1. Percepción del estado de salud de los miembros del primer contingente de la Fuerza de Tarea Conjunta TOROGOZ 2015.

\begin{tabular}{|c|c|c|}
\hline $\begin{array}{c}\text { Percepción del estado } \\
\text { de salud }\end{array}$ & Frecuencia & Porcentaje \\
\hline Excelente & 30 & 34.1 \\
Muy buena & 34 & 38.6 \\
Buena & 24 & 27.3 \\
Total & 88 & 100.0 \\
\hline
\end{tabular}

Fuente: Elaboración propia

Mackenbach afirma en un estudio realizado en Holanda que la morbilidad y mortalidad en la población pueden disminuir en un 25 a $50 \%$ si los hombres con bajos niveles educativos tuvieran la morbilidad y mortalidad de los hombres con educación universitaria ${ }^{9}$. Es decir que, a mayor nivel de estudios, mejor percepción de su propia salud posee.

Por otra parte, el $64 \%$ de los encuestados no tuvo ningún tipo de dolor en las últimas 4 semanas y solamente el $30 \%$ reporto dolor de cabeza.

El 23.9\% del contingente padecía de dificultades de sueño (Tabla 2). En un estudio llevado a cabo en Rio de Janeiro sobre el impacto de la profesión en la salud mental y psicológica de policías y militares, más del $40 \%$ de la población estudiada padecía trastorno de sueño derivados del estrés laboral y de las actividades propias de la profesión ${ }^{10}$.

Tabla 2. Dificultades para dormir en los miembros del primer contingente de la Fuerza de Tarea Conjunta TOROGOZ 2015 durante las semanas previas al estudio.

\begin{tabular}{|l|c|c|}
\hline Dificultad para dormir & Frecuencia & Porcentaje \\
\hline Casi siempre & 2 & 2.3 \\
Algunas veces & 19 & 21.6 \\
Nunca & 67 & 76.1 \\
Total & 88 & 100.0 \\
\hline
\end{tabular}

Fuente: Elaboración Propia.

En la variable sobre el nivel de conocimiento de salud bucal, el $95 \%$ de los encuestados relacionó lavado de dientes con la prevención de enfermedades bucodentales (Tabla 3). Y que las enfermedades periodontales son causadas por bacterias.

Tabla 3. ¿Lavarse los dientes regularmente evita la aparición de enfermedades de las encías?

\begin{tabular}{|l|c|c|}
\hline & Frecuencia & Porcentaje \\
\hline $\mathrm{Si}$ & 84 & 95.5 \\
No & 4 & 4.5 \\
Total & 88 & 100 \\
\hline
\end{tabular}

Fuente: Elaboración propia.

Solo el 20\% manifestó que la enfermedad periodontal es heredada. En este sentido, vale destacar, que la bibliografía señala a la enfermedad periodontal como multi-factorial donde intervienen factores microbiológicos, ambientales y genéticos ${ }^{11}$; afectando la aparición de la misma, su desarrollo y severidad. De igual forma el $23 \%$ de los sujetos entrevistados considera que la enfermedad periodontal es más frecuente en hombres que en mujeres.

En relación a ello, si bien no hay datos suficientes para considerar el sexo como factor de riesgo para la aparición de enfermedades gingivales y periodontales, en estudios longitudinales se ha demostrado que cuando se trata de las diferencias de sexo en la enfermedad periodontal, la preponderancia de la enfermedad se eleva debido a los hábitos masculinos como el factor cultural por encima de las causas biológicas, aumentándoles el riesgo de desarrollar formas más severas la enfermedad periodontal en comparación con las mujeres ${ }^{12}$.

En relación al tabaquismo y enfermedad periodontal, el $88 \%$ de ellos sabían que fumar cigarrillos aumenta la posibilidad de tener problemas periodontales. El $54.5 \%$ de ellos pensaban que inhalar humo de tabaco les hacia propensos a enfermedad periodontal y el $80 \%$ consideraban que fumar debilita los tejidos de soporte de la dentadura. Diversos estudios señalan al tabaquismo como factor predisponte en la aparición de la enfermedad debido a más 
de 4 mil sustancias toxicas que se generan en la combustión del cigarrillo ${ }^{13}$.

En cuanto a Diabetes, sólo el $65.9 \%$ de los encuestados sabe que la Diabetes puede causar enfermedad periodontal. Al respecto algunas investigaciones señalan la interrelación convirtiéndose la Diabetes como un Factor de riesgo ${ }^{9}$.

Seguidamente, el 65\% de los encuestados respondió que en las personas mayores de 40 años no es común padecer de enfermedad periodontal. En cuanto a enfermedades crónicas como las cardíacas, el $80 \%$ de ellos manifestó que estas enfermedades no están asociadas a problemas periodontales (Figura 1).

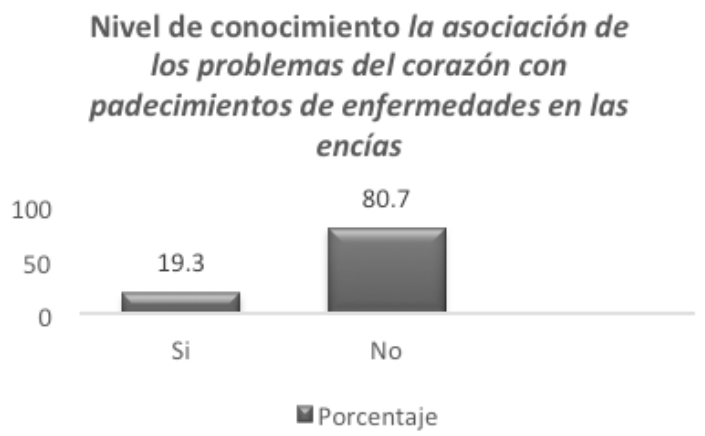

Figura 1. Nivel de conocimiento sobre asociación entre enfermedades de las encías y cardíacas. Elaboración propia.

No obstante, está comprobado que la calidad de la alimentación y ejercicio físico, condiciona un estilo de vida que repercute directamente sobre los mecanismos patogénicos mientras el síndrome metabólico está detrás de los problemas cardiovasculares asociado recientemente, con la periodontitis. Por tanto, aumenta el riesgo que ambas patologías puedan tener factores etiológicos comunes relacionados al estilo de vida ${ }^{14}$. Un dato sobresaliente es que el $80.7 \%$ de los integrantes del Contingente respondieron que la desnutrición no está vinculada a la inflamación de las encías (Tabla 4), cuando está ampliamente demostrado que en estados de desnutrición hay una disminución de las reservas nutricionales de los tejidos, que provocan una alteración pro- gresiva de la mucosa y disminuye la regulación del sistema de defensa ${ }^{15,16}$. De esta manera el hospedador puede ser susceptible a organismos oportunistas y por consecuentemente a procesos infecciosos, por falta de inmunización debido a alteraciones físicas provocadas por malnutriciones, estrés o cualquier otra enfermedad de base afectando la calidad de reparación de los tejidos ${ }^{16}$.

Tabla 4. Nivel de conocimiento sobre la vinculación entre desnutrición e inflamación de las encías del primer contingente de la Fuerza de Tarea Conjunta TOROGOZ 2015 durante las semanas previas al estudio.

\begin{tabular}{|c|c|c|}
\hline & Frecuencia & Porcentaje \\
\hline $\mathrm{Si}$ & 17 & 19.3 \\
$\mathrm{No}$ & 71 & 80.7 \\
Total & 88 & 100.0 \\
\hline
\end{tabular}

Fuente: Elaboración propia.

Sin embargo, el $55.7 \%$ de los encuestados respondió que la enfermedad periodontal si puede repercutir sobre el estado de salud general de los pacientes. Y prueba de ello es que el $65 \%$ reconoció que el sangrado de encías es signo de enfermedad.

El 80\% de ellos piensa que el apiñamiento dental dificulta la higiene bucal. No obstante, el $40 \%$ de los encuestados desconoce que la enfermedad periodontal afecta la salud de la madre durante el embarazo (Tabla 5).

Tabla 5. Nivel de conocimiento sobre asociación entre enfermedad de las encías y la salud de la madre durante el embarazo.

¿Tener problemas de encías afecta la salud de la madre durante el embarazo?

\begin{tabular}{|l|l|l|}
\hline \multicolumn{2}{|c|}{ Porcentaje } \\
\hline Válidos & $\mathrm{Si}$ & 61.4 \\
& No & 38.6 \\
& Total & 100 \\
\hline
\end{tabular}

Fuente: Elaboración propia.

En cuanto a la variable de estado de salud bucal del contingente, el índice de caries de la historia pasada CPOD que cuenta las piezas dentales 
cariadas, perdidas y obturadas, total fue de 17.34 (Figura 2). Un dato preocupante dado que el índice señalado por la Organización Mundial de la Salud (OMS) como aceptable no puede superar los 3 dientes Cariados, Perdidos y Obturados CPO-D a los 12 años.

\section{Indice CPO-D}

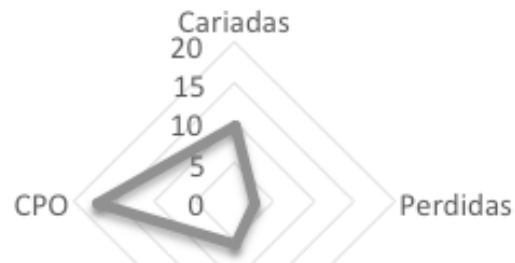

Obturadas

Figura 2. Índice CPO-D en los integrantes del primer contingente de la Fuerza de Tarea Conjunta TOROGOZ, 2015. Elaboración propia.

Este dato es reflejo de lo que se plantea a nivel mundial sobre la alta prevalencia de caries dental, ya que el $100 \%$ de la población entrevistada presentó caries dental por lo que el $40 \%$ de la población total ha perdidó una o más piezas dentales por caries dental y en el mismo porcentaje padecía de enfermedad periodontal en sus manifestaciones más comunes como Gingivitis.

Un aproximado del $15 \%$ de los encuestados padecía movilidad dental y el $40 \%$ de ellos afirmó padecer Halitosis.

Respectoala sensibilidad dental aproximadamente el 30\% de los encuestados presentaban diferentes grados de sensibilidad al cambio de temperatura, a los sabores, al morder y/o al cepillado. En cuanto a la frecuencia del cepillado el $67 \%$ de la población encuestada manifestó hacerlo tres veces al día. Más del $80 \%$ de los encuestados manifestó no tener hábitos parafuncionales y el $87.5 \%$ dijo utilizar seda dental.

\section{CONCLUSIONES}

Se concluye que la prevalencia de caries dental en la población militar perteneciente al primer contingente de la Fuerza de Tarea Conjunta TOROGOZ 2015, la cual se estableció por medio del índice CPOD fue de 17.34, con una cantidad mayor de piezas dentales con caries, con obturación o perdidas, considerando que para la OMS como aceptable menos de 3. Por tanto, se infiere que es necesario el reforzamiento de los programas de educación y promoción de la salud bucal. Así como la implementación de un programa de seguimiento y control a los pacientes hasta la conclusión del Plan de Tratamiento, dado que la caries dental no es una enfermedad que se cure, solamente se controla cuando todos los entes involucrados cumplen con las funciones específicas de su rol.

La población estudiada conoce los beneficios de la higiene bucal para mantener la salud bucodental. Esto demuestra que los programas de odontología preventiva dentro de la Fuerza Armada han tenido un avance significativo. Sin embargo, todavía no se ha priorizado la prevención en la salud bucal como prioridad en las unidades militares.

No se puede omitir que el trabajo del Ministerio de Salud e instituciones privadas con programas de prevención contribuyen a la educación en salud bucal y a la atención odontológica de la Fuerza Armada que regularmente hace uso de sus establecimientos. Así mismo, la información que difunden medios de comunicación masivos para informar y prevenir.

La población del Contingente presentó un aceptable estado de salud general que debía ser controlado por los profesionales de salud a cargo.

En cuanto a los hábitos y prácticas de salud bucal, la mayoría dijo tener buenos hábitos que contrasta con los altos índices de caries encontrados. Por tanto, se debe trabajar en la motivación y la implementación de hábitos y prácticas en salud bucal. 
Sin duda el nivel de conocimientos sobre salud bucal entre la población militar perteneciente al Contingente debe ser reforzado. Sobre todo para identificar las enfermedades bucales como agentes causantes o coadyuvantes de serias complicaciones del estado general de salud por condiciones sistémicas como: Diabetes Mellitus o enfermedades cardíacas.

\section{RECOMENDACIONES}

- A los tomadores de decisiones en el Batallón de Sanidad Militar: estandarizar y actualizar la información de los programas de odontología preventiva dentro de las diferentes unidades militares de la Fuerza Armada incluyendo a los Contingentes que participan en Misiones Internacionales, ampliando la información de salud bucal y la relación del estado de los tejidos de la boca con las enfermedades crónicas y embarazo, en las diferentes unidades militares incluyendo a los contingentes que participan en Misiones Internacionales.

- Incluir dentro del Programa de Evaluaciones de la Fuerza Armada un comprobante semestral de profilaxis dental para mayor efectividad de la odontología preventiva, considerando que esto reduce costos de atención curativa.

- Coordinar con otras instituciones de salud o educación para mantener actualizados los Programas de Odontología Preventiva y Apoyo cuando se requiera reforzarlos para convertirlos en agentes multiplicadores en sus familias y comunidades.

- Al Contingente, velar por mantener un adecuado control de su salud integral, poniendo en práctica los conocimientos y hábitos saludables adquiridos previamente a lo largo de la vida, tanto dentro y fuera del país, siendo controladas por medio de Sanidad Militar.

- A la Universidad Evangélica de El Salvador, se recomienda cooperación interinstitucional con el Batallón de Sanidad Militar como socios estratégicos para velar por la salud de esta población.

- Alas instituciones que velan por la salud bucal de la población salvadoreña, se recomienda tomar el resultado de este diagnóstico como una microfotografía de la situación actual de salud bucal de la población militar y se propongan acciones concretas para la promoción, motivación y educación en salud bucal como una herramienta efectiva en la prevención de enfermedades bucodentales.

\section{REFERENCIAS BIBLIOGRÁFICAS}

1. Caro AY, Agudelo AA, Benavides FG. Relación entre las condiciones de trabajo y el estado de salud en la población trabajadora afiliada al Sistema General de Riesgos Profesionales de Colombia Rev. Fac. Nac. Salud Pública, 2011; 29(4): 392-401.

2. Who.int Centro de prensa, Determinantes Sociales de la Salud, WHA62.14 New York, 2009 [Actualizado el 9 de Mayo de 2009; acceso 15 de Febrero de 2015] Disponible en http://www.who.int/social_determinants/es/

3. Benavides FG. Informe de Salud Laboral. España, 2006. Barcelona: Observatorio de Salud Laboral; 2007.

4. Boletín Informativo No. 2 de Sanidad Militar, El Salvador, mayo de 1992.

5. Centro de Noticias ONU. Disponible en: http://www. un.org/spanish/News/story.asp?NewsID=31638\#. WOeryqK1vIU, consultado: septiembre 2015.

6. MINUSMA. Misión Multidimensional Integrada de Estabilización de las Naciones Unidas en Malí. Disponible en: http://www.un.org/es/peacekeeping/ missions/minusma/background.shtml, consultado en septiembre 2015.

7. FAES solicita permiso a Asamblea para participar en misión de la ONU en Mali, África. Disponible en: http://diario1.com/politica/2014/12/faes-solicitapermiso-a-asamblea-para-participar-en-mision-dela-onu-en-mali-africa/, consultado en enero 2015.

8. Who.int, Centro de Prensa, Salud Bucodental, Nota Informativa No 318 , febrero de 2007. Consultada en enero de 2014. Disponible en http://www.who.int/ mediacentre/factsheets/fs318/es/ 
9. Mackenbach J. Socioeconomic inequalities in health in the Netherlands: Impact of a five year research programme. BmJ, 1994; 309(6967): 1487-1491. 17 Kunkel SR, Atchley RC.

10. Minayo MC, Assis SG, Oliveira R V. Impacto das atividades profissionais na saúde física e mental dos policiais civis e militares do Rio de Janeiro (RJ, Brasil). Ciênc. saúde coletiva [Internet]. 2011 Apr [acceso 2015 Nov24] ; $16(4$ ): 2199-2209. Disponible en: http://www.scielo.br/scielo.php?script=sci_ arttext\&pid=S1413-81232011000400019\&lng=en .

11. Rodrigo-Gómez D, Oteo-Calatayud A, AlonsoRosado A, Bascones-Martinez A. El papel de la genética en la aparición y desarrollo de la periodontitis: I: evidencias científicas de la asociación entre periodontitis y genética. Avances en Periodoncia [revista en la Internet]. 2007 Ago [citado 2015 Nov 24] ; 19(2): 71-81. Disponible en: http://scielo. isciii.es/scielo.php?script=sci_arttext\&pid=S1699$65852007000300002 \& \operatorname{lng}=\mathrm{es}$.
12. Cenk H, Ozcelik O, Mariotti A. Periodontal disease in men. Periodontology, 2000. Volume 61, Issue 1, pages 52-265, February, 2013.

13. Genco RJ, Borgnakke WS. Risk factors for periodontal disease. Periodontology, 2000. Volume 62, Issue 1, pages 59-94, June, 2013.

14. C. de Teresa E. Noguerol B. Enfermedades cardiovasculares, enfermedades periodontales y estílo de vida. CAPÍTULO 15. Patología Periodontal y Cardiovascular. España, 2011. Editorial Médica Panamericana.

15. Selva Sutter EA. La Epidemiologia Socionatural en el nuevo Milenio. Primera edición, San Salvador, El Salvador: UCA Editores, 2005114 página.

16. Negroni, M. Microbiología Estomatológica; Fundamentos y Guía práctica. 2da ed. Argentina. Editorial Médica Panamericana; 2009. 